\title{
Visão sistêmica na Educação Básica: uma proposta de inclusão escolar
}

\author{
Tomás Dias D’Abreu ${ }^{1}$ \\ https://orcid.org/0000-0002-7834-9355 \\ Deise Nanci de Castro Mesquita ${ }^{2}$ \\ https://orcid.org/0000-0001-6872-7001
}

\section{Resumo}

Este artigo apresenta e discute o Trabalho de Conclusão de Ensino Médio (TCEM) desenvolvido no Centro de Ensino e Pesquisa Aplicada à Educação, entre 2017 e 2018, com a aprovação de banca examinadora em 2019. Os dados foram coletados durante os encontros organizados por um secundarista e três outros bolsistas de iniciação científica, sob a orientação da pesquisadora coordenadora. Intitulado AEE: alegria de estudar com equidade, o projeto atendeu a alunos $\operatorname{dos} 6^{\circ}$ aos $9^{\circ}$ anos, no contra turno escolar, por adesão, objetivando promover atividades integrativas entre pessoas com e sem deficiências. A proposta foi fundamentada no paradigma sistêmico que, segundo Vasconcellos (2002), se sustenta em três eixos: a complexidade que se dá nas relações entre o observador e seu contexto, com o foco no objeto observado; a instabilidade que implica no reconhecimento de que o objeto está, e não é, admitindo-se, pois, a maleabilidade do que se estuda ou se observa; e a intersubjetividade que se refere à constatação de que o conhecimento é sempre inacabado, por se constituir de concepções advindas de experiências coletivas integradas lentamente em um grande tecido. As observações e análises demonstram que a despeito de a intervenção realizada pelos responsáveis ter tomado em conta as formulações de Mantoan (2003) sobre a inclusão escolar com foco no respeito às singularidades e na valorização das potencialidades individuais, durante a realização de atividades em grupo o que se percebeu, na maior parte do processo, foram atitudes de discriminação, segregação e desrespeito, motivadas principalmente pelo desejo de competição e sobreposição aos demais.

Palavras-chave: Abordagem sistêmica, Inclusão escolar, Educação Básica.

\section{Systemic vision in Basic Education: a proposal for school inclusion}

\footnotetext{
Abstract

This article presents and discusses the High School Term Paper (Trabalho de Conclusão do Ensino Médio - TCEM) developed at the Centro de Ensino e Pesquisa Aplicada à Educação (CEPAE) at Universidade Federal de Goiás (UFG), between 2017 and 2018, with the approval of an examination board in 2019. Data were collected during meetings organized by a high school senior and three other scholars, under the guidance of the coordinating researcher. Entitled AEE: alegria de estudar com equidade (joy of studying with equity), the project attended students from the 6th to the 9th grades, through free admission, out of school

${ }^{1}$ Graduando em Psicologia pela Universidade Federal de Goiás. E-mail: tomasdias26@gmail.com.

${ }^{2}$ Doutora em Letras e Linguística pela Universidade Federal de Goiás e professora pesquisadora no Programa de Pós-Graduação em Ensino na Educação Básica do Centro de Ensino e Pesquisa Aplicada à Educação da Universidade Federal de Goiás. E-mail: mesquitadeise@ufg.br.
} 
schedules, aiming to promote integrative activities between people with and without disabilities. The proposal was orientated by the systemic paradigm that, according to Vasconcellos (2002), is based on three axes: complexity that occurs in the relationship between the observer and his context, with a focus on the observed object; instability that implies the recognition that the object is being, and not simply is, admitting, therefore, the malleability of what is studied or observed; and intersubjectivity that refers to knowledge as always being unfinished, as it consists of conceptions arising from collective experiences that are slowly integrated into a large tissue. Observations and analyzes show that, despite the intervention carried out by those responsible for taking into account Mantoan's formulations (2003) on school inclusion, which focus on respecting singularities and on valuing individual potentialities, in most of the process during group activities attitudes of discrimination, segregation and disrespect were noticed, mainly motivated by the desire for competition and overlapping the others.

Keywords: Systemic approach, School inclusion, Basic Education.

\section{Introdução}

Este artigo apresenta e discute o Trabalho de Conclusão de Ensino Médio (TCEM) intitulado A Tendência Educacional Positivista em Contraste com a Formação Humana, cujo objetivo foi investigar, a partir de uma proposta de Atendimento Educacional Especializado (AEE), a seguinte questão: "Se e como uma escola que valoriza as diferenças e reconhece as individualidades pode potencializar o desenvolvimento de todos os envolvidos?”. Para tanto, é descrito e analisado o Projeto de Ensino e Pesquisa: AEE: alegria de estudar com equidade, desenvolvido por pesquisadores de iniciação científica, um aluno de ensino fundamental dos anos finais, um secundarista e duas graduandas, durante o $2^{\circ}$ semestre de 2017 e o $1^{\circ}$ semestre de 2018, no Centro de Ensino e Pesquisa Aplicada à Educação (CEPAE/UFG).

$O$ foco desse AEE foi explorar e potencializar as capacidades cognitivas e criativas de todos os envolvidos, a partir de uma perspectiva sistêmica de educação inclusiva, oferecendo vinte vagas para qualquer aluno $\operatorname{dos} 6^{\circ}$ aos $9^{\circ}$ anos do Ensino Fundamental, e não somente aos considerados "atrasados" dentro de seus ciclos educacionais regulares, diagnosticados, ou não, com síndromes, transtornos, distúrbios mentais, ou outras razões passíveis de causar, segundo o senso comum, "um impacto negativo" na cognição desses indivíduos ou aos grupos a que pertencem.

Em sua essência, o projeto assumiu um compromisso antissegregacionista, pois se negou a continuar confirmando a triste realidade demonstrada em pesquisas federais, que apresentam dados como os da Pesquisa Nacional por Amostra de Domicílios (PNAD), feita pelo IBGE em 2015 , em que cerca de $51 \%$ dos brasileiros com 25 anos ou mais não concluem sequer o ensino fundamental; um dado que comprova os altos índices de evasão escolar e do não atendimento da população por uma rede pública de ensino, problemas frequentes em países muito desiguais socialmente. 
Isto pode até não assustar àqueles já acostumados com os corriqueiros reveses sociais brasileiros, mas quando vemos que países com altos índices de escolaridade estão muito longe de uma situação socioeconômica crítica tal qual a que vivemos há décadas no Brasil, que deixa no ar um clima de tensão repleto de intolerâncias confirmadas com atos cada vez mais bárbaros e constantes, principalmente em períodos de atrito político como nos processos eleitorais, nos damos conta de que a educação é um dos principais agentes transformadores da sociedade e entendemos que projetos como estes são imprescindíveis, se quisermos tirar países como o Brasil da lista dos mais desiguais do mundo, em que ocupamos a $10^{\mathrm{a}}$ posição, segundo registros da ONU, em 2016.

Produzidos durante o Projeto AEE, os dados deste trabalho foram retirados de diários de campo, usados no estudo da problemática da pesquisa e tomados como elementos-chave para a sua conclusão. As observações feitas foram baseadas nos três pilares do pensamento sistêmico de Vasconcellos (2002): complexidade, instabilidade e intersubjetividade; bem como na ótica inclusiva de educação de Mantoan (2003).

\section{AEE, inclusão e o pensamento sistêmico}

Em primeiro lugar, é preciso enfatizar a recorrência do uso de "educação para todos" neste texto, pois, novamente, se ainda há pesquisas como estas já citadas, podemos dizer que o artigo 205 da Constituição Federal de 1988 não tem sido cumprido como dita a lei. E essa define integralmente que:

A educação, direito de todos e dever do Estado e da família, será promovida e incentivada com a colaboração da sociedade, visando ao pleno desenvolvimento da pessoa, seu preparo para o exercício da cidadania e sua qualificação para o trabalho.

Dito isso, ficam algumas questões para reflexão: que tipo de preparo para o exercício da cidadania e para o mundo do trabalho o Estado tem garantido para seus cidadãos, se quase metade de sua população não tem uma formação acadêmica básica? Que tipo de desenvolvimento pleno é esse, se pelo acesso à educação milhões de pessoas podem não saber sequer ler ou escrever? Quanto a isso Mantoan adverte:

Quando garante a todos o direito à educação e ao acesso à escola, a Constituição Federal não usa adjetivos e, assim sendo, toda escola deve atender aos princípios constitucionais, não podendo excluir nenhuma pessoa em razão de sua origem, raça, sexo, cor, idade ou deficiência. (MANTON, 2003, p. 22). 
Pertinentemente, Mantoan denuncia uma contradição localizada na base da estrutura educacional. A manutenção de tal inconstitucionalidade é, por si só, inadmissível em uma sociedade democrática. Portanto, a educação, que deveria ser por definição um direito de todos, acaba sendo excludente para muitos, de tal forma que o próprio sistema educacional a torna segregacionista, uma vez que ao manter tamanha ilegalidade gera, ele mesmo, os excluídos.

No que diz respeito aos excluídos, sobretudo às pessoas com deficiências, as injustiças tendem a ser superadas muito lentamente, pois na maioria das vezes são vistas primeiramente como um "deficiente", um "incapaz", alguém a quem seria de "bom tom" oferecer ajuda, e não um cidadão que, como qualquer outro, possui direitos conquistados ao longo da história com muita luta e que, portanto, deve ter suas necessidades especiais respeitadas e atendidas. Desse modo, a manutenção da distância entre a realidade e a lei se torna ainda maior, sobretudo quando elege a igualdade como um de seus princípios fundamentais. Mantoan vai ao encontro da realidade prática, quando se refere à persistência da exclusão dentro da escola formal e quando justifica a relevância da discussão:

Percebi, e reluto em admitir, as medidas excludentes adotadas pela escola ao reagir às diferenças. De fato, essas medidas existem, persistem, insistem em se manter, apesar de todo o esforço despendido para se demonstrar que as pessoas não são "categorizáveis". (MANTOAN, 2003, p. 8).

Diante disso, esta equipe de bolsistas de iniciação científica organizou o projeto de pesquisa e extensão AEE: alegria de estudar com equidade com vistas à participação de alunos do ensino fundamental dos anos finais, com e sem deficiência, em atividades de interação social e desenvolvimento cognitivo, no contra turno da escola, como uma forma de colaborar com a medida prevista no artigo 208 da Constituição Federal de 1988, que explicita como dever do Estado a garantia de "atendimento educacional especializado aos portadores de deficiência, preferencialmente na rede regular de ensino". Quanto a isso, Mantoan justifica que:

O "preferencialmente" refere-se a "atendimento educacional especializado", ou seja: o que é necessariamente diferente no ensino para melhor atender às especificidades dos alunos com deficiência, abrangendo principalmente instrumentos necessários à eliminação das barreiras que as pessoas com deficiência naturalmente têm para relacionar-se com o ambiente externo [...]. (MANTOAN, 2003, p. 23).

As atividades propostas durante os encontros do projeto, descritas a seguir, vão nesse sentido. A primeira, chamada "quebra gelo", se constituiu em uma dinâmica de apresentação entre todos os presentes no momento; teve 
o papel de promover uma interação geral entre os membros do grupo, para criar um ambiente receptivo e amistoso, evitando manter condicionadas as barreiras sociais entre os alunos de séries distintas e os Portadores de Necessidades Especiais (PNE). E a segunda foi uma dinâmica para a apresentação das intenções do projeto e do sentido dado ao conceito "paradigma sistêmico", assim sintetizado por Vasconcellos:

Quadro 23 - O cientista novo-paradgimático

1. Amplinado o foco de observação: vendo sistemas de sistemas, contextualiza o fenômeno e focaliza as interações recursivas.

2. Acreditando nos processo autônomos: trabalha com amudança no sistema e admite que não controla o processo.

3. Adotando o caminho da "objetividade entre parênteses": reconhecese parte do sistema e atua na perspectiva da coconstrução das soluções. (VASCONCELOS, 2020, p. 152)

\section{AEE: alegria de estudar com equidade}

No primeiro encontro havia muitas crianças, a maioria voluntária das turmas dos $6^{\circ}$ anos. Todas estavam muito agitadas e pareciam empolgadas com a sala de aula cheia. Os bolsistas também, já que não esperavam tamanha adesão ao projeto, que se iniciava com quase vinte alunos. E depois de organizar a sala de aula em um semicírculo, cada um se apresentou com nome e ocupação. Em seguida foi explicado que o projeto tinha como objetivo reunir um grupo de pessoas para que pudessem apreender e se desenvolver juntos, a partir das habilidades e interesses definidos por cada um. A apresentação deixou clara a distinção entre o projeto e as atividades do ciclo matutino de aulas, o que era extremamente importante para que as crianças entendessem a oportunidade que tinham de exercer sua autonomia, podendo se apropriar de seus talentos para aprender o que tivessem interesse, longe do ambiente limitador da escola formal em que estavam imersos. Para Mantoan:

O sucesso da aprendizagem está em explorar talentos, atualizar possibilidades, desenvolver predisposições naturais de cada aluno. As dificuldades e limitações são reconhecidas, mas não conduzem nem restringem o processo de ensino, como comumente se deixa que aconteça. (MANTOAN, 2003, p. 37).

Por essas razões, o projeto tinha de garantir que as dúvidas, vontades e potencialidades dos alunos tivessem vazão, para poderem ser expressas e desenvolvidas em grupo. Assim, o ensino proposto no AEE não partiu de disciplinas, mas sim do que era trazido pelos alunos ao longo dos encontros, e as atividades ocorrerem por meio de dinâmicas conjuntas e educativas, como por exemplo jogos e a produção de trabalhos artísticos de livre escolha, 
como curtas, peças teatrais, desenhos, colagens, poemas, músicas e outros que eles tenham interesse em desenvolver. Como alternativas para potencializar a inclusão, Mantoan indica:

Debates, pesquisas, registros escritos/falados, observação, vivências são alguns processos pedagógicos indicados para a realização das atividades escolares. Tais processos dependem dos conteúdos curriculares para esclarecer os assuntos em estudo, mas os conteúdos são sempre considerados como meios, e não como fins do ensino escolar. (MANTOAN, 2003, p. 39).

Para o primeiro momento de apresentações, foi entregue um pedaço de papel para que cada aluno respondesse: 1. Qual a sua idade?; 2. O que mais gosta de fazer; 3. Se fosse um animal, qual seria e por quê?; e 4. O que as pessoas mais gostam em você? Em seguida, os papéis foram recolhidos e redistribuídos aleatoriamente, assim cada um teria de ler o papel que recebeu e, uma vez que todos estivessem sentados em círculo, deveria tentar adivinhar quem era o autor das informações. É neste ponto que se encaixaria o próximo objetivo, pois as perguntas, além de servirem para instigar as crianças a tentar enxergar todos ali presentes evitando a exclusão, teriam o papel de apresentar algumas características de cada pessoa com quem futuramente todos trabalhariam. A figura (Fig.1) demonstra como se divertiam, se soltavam e interagiam, dando atenção e demonstrando interesse na atividade. 
Fig.1 - Quem sou eu? (acervo do pesquisador)

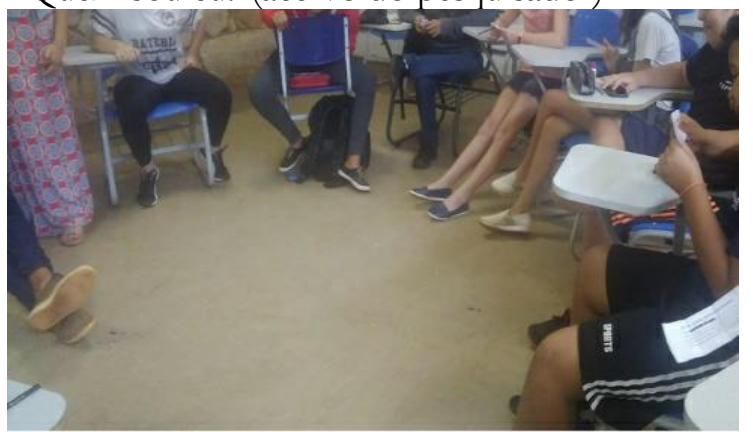

A partir das respostas, puderam ser identificadas características gerais como criatividade, proatividade, sensibilidade, habilidades em atuação, desenho, dentre outras. E, como forma de criar um gancho para uma dinâmica posterior, o outro objetivo consistiu em motivar os alunos a fazerem julgamentos e análises sobre os outros membros do grupo.

Para a dinâmica denominada Mandala Sistêmica, o plano foi conseguir uma forma de unir o primeiro momento do encontro com uma apresentação prática dos objetivos do trabalho, demonstrando o que significava dizer "um grupo inclusivo de pessoas buscando aprender juntas". A atividade consistia em fazer uma construção conjunta de um item selecionado previamente, com o intuito de exemplificar os três pilares do pensamento sistêmico (VASCONCELLOS, 2002) de maneira prática e concreta, não abstrata. Sendo assim, os alunos se colocaram em roda com o livro "Quem Roubou o meu Futuro", de Sílvia Orthof, ao centro, e cada um que recebia a ponta de um barbante deveria fazer uma observação sobre o objeto (o livro físico), sem contudo ler mais do que as informações da capa ou repetir uma informação ou negar algo que já havia sido dito. Feito isso, o aluno deveria passar o barbante para outra pessoa de sua escolha, que repetiria o processo até que todos também participassem. 
Fig. 2 - Mandala Sistêmica (acervo do pesquisador)

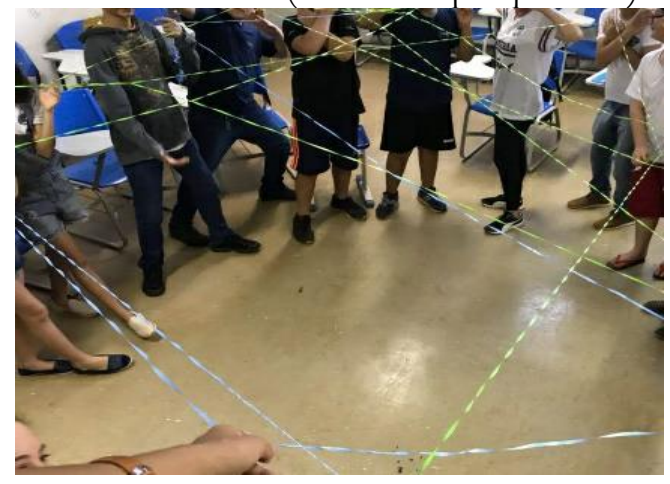

Desta maneira eles construíram uma rede de relações e puderam constatar que: o conhecimento acerca do objeto expandiu-se em relação ao que era conhecido antes (complexidade); o resultado foi fruto dos esforços e da colaboração de todos, logo o conhecimento é mais complexo e completo do que cada uma das partes poderia deduzir sozinha (intersubjetividade); e a expansão do conhecimento através de múltiplas subjetividades acarreta uma transformação no objeto observado, isto é, a mandala que se apresentava naquele momento era fruto de uma organização de determinados movimentos dos sujeitos que seguravam o barbante, mas se tivessem sido dispostos de outra forma provocariam um outro resultado (instabilidade).

Ao contextualizar o fenômeno, aplicando o foco, o observador pode perceber em que circunstância o fenômeno acontece, verá relações intrasistêmicas e intersistêmicas, verá não mais um fenômeno, mas uma teia de fenômenos recursivamente interligados e, portanto, terá diante de si a complexidade do sistema (VASCONCELLOS, p. 151)

Segundo a visão sistêmica, a complexidade se dá nas relações entre o observador e seu contexto, com o foco no objeto observado. Diferentemente, pois, de uma análise "positivista tradicional" cuja a observação tem um foco unilateral do observador para o objeto, como um feixe de luz que passa por uma fechadura de uma porta trancada e ilumina a sala na qual está uma maçã, e deixa à vista apenas este objeto sobre a mesa de centro da sala, por exemplo. O que demonstra como, no paradigma tradicional da ciência, o olho que atravessa o pequeno feixe de luz só é capaz de ver e compreender a imagem disponível naquela fração minúscula, e não na totalidade da sala.

De outra maneira, o cientista sistêmico amplia seu foco em relação ao que se observa, deixando que as relações entre a maçã, a mesa e o observador entrem no experimento; ou seja, olhando para a mesa, ele pode ainda perceber que o motivo de a maçã ter sido feita de cera e estar sobre a mesa é porque se trata de um simples componente decorativo; ainda, caso o observador seja 
daltônico, ele acabará se dando conta de que a cor verde do objeto não passa de uma interpretação particular de seu cérebro que decodifica os padrões de fótons capturados pelos olhos. Portanto, ao se permitir ampliar o foco para as relações que envolvem o que se observa, o cientista sistêmico acaba por compreender melhor o universo incerto da sala, a própria materialidade daquilo que pesquisa e a ele mesmo, justamente porque reconhece que a maçã verde de cera não é um objeto isolado pela porta, separado da realidade da sala e do observador, mas sim um dos componentes da realidade maior que abarcam todos estes e muitos outros, em que todos estão de alguma maneira relacionados, em sistemas.

Com relação à complexidade presente na dinâmica sistêmica da mandala, podemos elencar os próprios alunos, a parte externa do livro, o título, a ilustração e qualquer aspecto relacionado com o objeto observado.

Ao distinguir um dinamismo das relações presentes no sistema, o observador estará vendo um processo em curso, um sistema em constante mudança e evolução, autônomo, com o qual não poderá pretender ter uma interação instrutiva, e estará, portanto, assumindo a instabilidade, a imprevisibilidade e a incontrolabilidade do sistema. (VASCONCELLOS, 2002, p. 151)

De fato, tudo o que compõe nosso mundo palpável é composto por estruturas materiais comuns, que ao longo do tempo apenas passam por reorganizações constituindo todos os corpos físicos, os átomos, minúsculas partículas com massa que ao alterar as interligações formam o mundo macroscópico em que vivemos. Contudo, as partículas com carga negativa de todos os átomos, chamados elétrons, são pequenos componentes que apesar de possuírem massa (ainda que muito pequena), a todo o momento mudam de comportamento no mundo natural, atuando ora como um objeto com massa ora como onda (o som é uma onda, por exemplo), deixando para trás seus corpos e propriedades materiais. Este fenômeno constatado, mas ainda não explicado pela ciência, é um dos muitos exemplos de que o que compreendemos como sendo real é instável, mutável, imprevisível em sua totalidade, e por isso incontrolável.

Em vista disso, Vasconcellos (2002) define que o cientista sistêmico não imprime uma condição de "ser estável" nas coisas, uma definição concreta e imutável, mas reconhece a condição de "estar" do objeto, admite a maleabilidade do que se estuda ou observa, como um simples cubo de gelo que nada mais é do que uma porção de água que ao ser resfriada muda de estado, uma outra forma do que antes chamávamos água. Fica a questão: e se ao invés de objetos (materializados) como a mandala, a maçã ou o gelo, for tomado como objeto (imaterial, abstrato) para análise a aprendizagem? É realmente possível controlar e prever o que e como uma pessoa aprende? Pela dinâmica da mandala, foi possível demonstrar isso aos participantes, que tanto 
as relações quanto o conhecimento comum entre todos os alunos sobre o livro se expandiram e mudaram de um estado inicial individual para um "final" mais amplo e coletivo.

Ao reconhecer sua própria participação na constituição da "realidade" com que está trabalhando, e ao validar as possíveis realidades instaladas por distinções diferentes, o observador se inclui verdadeiramente no sistema que distinguiu, com o qual passa a se perceber em acoplamento estrutural, e está atuando nesse espaço de intersubjetividade que constitui o sistema com que trabalha. (VASCONCELLOS, 2002, p. 151).

O terceiro eixo, a intersubjetividade, explica bem a diferença entre os dois paradigmas científicos, o sistêmico e o positivista: se é consenso que a "realidade" é de fato tão complexa e instável como descrito anteriormente, então a "verdade absoluta" se torna algo improvável de se alcançar; logo, o homem, ser imperfeito que busca o conhecimento incansavelmente, é incapaz de construir sozinho toda uma concepção, e é por isso mesmo que escreve o que pensa apoiando-se em um referencial teórico, em fragmentos de outras mentes diversas que teorizaram também, embasando-se em um coletivo maior. E, quanto à intersubjetividade relativa à atividade, têm-se as fitas representando a teia de interrelações formada pelos alunos, ampliando o conhecimento sobre o livro.

No encontro seguinte foi iniciado o primeiro trabalho de produção feita com os alunos. O mesmo livro "Quem roubou o meu futuro?" foi tomado e os capítulos foram divididos e entregues a grupos de quatro a cinco pessoas (alunos + um bolsista). Estes grupos deveriam ler e reproduzir o trecho do texto recebido, de maneira livre, utilizando-se de qualquer recurso que quisessem, com o objetivo de provocar uma inclusão entre todos, atender aos interesses dos próprios alunos e estimular o uso de habilidades individuais para uma produção coletiva. Também era importante que houvesse a compreensão dos membros quanto à atividade anterior, para que mesmo sem a consciência e o conhecimento teórico sobre o pensamento sistêmico, pudessem notar a complexidade do grupo e sua instabilidade, para a criação de uma rede intersubjetiva que culminasse em um trabalho final que traduzisse suas potencialidades.

Os grupos foram formados e decidiram que o primeiro faria uma pequena adaptação mímica da cena que consistia em uma discussão familiar entre a protagonista, sua avó e sua mãe, que se finalizava com um bater de portas tipicamente adolescente, seguido de uma reconciliação. Logo no início foi possível perceber que a ideia era ótima, pois um dos garotos resolveu recriar uma das personagens de maneira genial, a avó da protagonista. A espontaneidade de seus gestos foi surpreendente, ele curvou as costas, colocou uma das mãos na lombar, franziu o rosto, fingiu apoiar-se em uma 
bengala, depois amarou um lenço na cabeça e criou um gruindo combinado com um gesto de mão como de quem dá uma advertência. Perguntado se já havia tido alguma experiência com teatro, ele disse que estava tendo o contato pela primeira vez naquele ano, e que apenas se lembrara das tardes que havia passado com suas avós na infância para criar a personagem.

Um outro grupo narrou o momento em que a protagonista do livro tentava entrar para um grupo com outras quatro amigas, que a excluíam e a rejeitavam. Esta mensagem foi passada muito bem, pois durante o ato ficaram claros o clima de exclusão e as relações de afinidade e poder entre elas, com vários momentos de abuso de poder e autoridade. $\mathrm{O}$ que evidenciou uma ótima organização, interpretação de texto, coesão, atuação e, ironicamente, inclusão. No entanto, era possível vê-las sempre discutindo ou brigando enquanto ensaiavam, por questões relativas à apresentação, como os papéis ou as ações que os demais membros do grupo deveriam fazer. O grupo era formado apenas por um mesmo ciclo de convivência, indo contra as orientações dos bolsistas e as propostas inclusivas da atividade. Uma vez que eram todas alunas de uma mesma turma, com idades semelhantes, mesmo sexo, mesma condição física, dentre outras características em comum, que foram positivas para a proposta sistêmica como grupo mas que, ao final, infelizmente, o total se apresentou bem mais complexo do que a soma de suas frações; isto porque o fruto das três individualidades, potencialidades, que souberam fazer um bom uso dos seus talentos naturais, configurou-se também maléfico para a proposta inclusiva, já que devido à atitude das três uma gama de alunos diversos não foram incluídos!

O terceiro grupo preparou um "semi-improviso", uma cronologia básica dos acontecimentos de seu texto, mas os diálogos foram improvisados. Esta proposta foi extremamente coerente com a cena, já que se tratava de uma conversa entre a protagonista e o grupo de teatro em que ela tentava entrar. Então o diálogo e a interação entre os membros do grupo ficaram extremamente naturais e fluidas. Porém, como o grupo era todo masculino, o bolsista sugeriu que ele próprio fizesse uma protagonista usando uma peruca. O resultado foi um assustador episódio de assédio moral, uma violência distribuída por um garoto com menos de treze anos de idade, que humilhava e ridicularizava a figura feminina, reproduzindo a misoginia de uma forma difícil de se imaginar possível entre crianças, as mesmas crianças que desavisadamente riam, sem aparentemente conseguir compreender a gravidade do que acontecia ali. O bolsista ficou extremamente irritado, pois também não imaginava tamanha humilhação. Mas o que mais causou surpresa foi a maneira com que todo o grupo se divertia, gargalhava e, até mesmo depois da saída da personagem ridicularizada, utilizava as habilidades e talentos de cada integrante, como a espontaneidade e a criatividade, que de fato eram muito bem explorados por eles, como ferramentas para transformar aquela pessoa em um motivo de chacota e escárnio generalizado. Para os bolsistas, ficou evidente a conclusão de que os pilares sistêmicos podem ser 
usados não só para incluir, mas também excluir, segregar, abusar e violentar outras pessoas, mesmo partindo de crianças.

Nesse dia, ainda tivemos um grupo de vídeo, que reproduziu sua cena usando bonecos feitos por eles, para representar um relato do diário da protagonista. Mas, infelizmente, não foi possível reaver o vídeo para fazer uma avaliação e análise.

Foi a partir do quinto encontro que a equipe decidiu iniciar uma outra etapa do AEE: trabalhar a sensibilidade e empatia como forma de tentar combater as violências que haviam ocorrido durante os encontros. Além da apresentação de improviso que se transformou em assédio moral, era evidente uma constante hostilidade na forma como eles se comunicavam, sempre aos gritos, passando por cima uns dos outros. Tal atitude ainda viria a se apresentar em alguns encontros depois, na forma de constantes desentendimentos, posturas agressivas de alguns integrantes e em uma situação de exclusão com um dos alunos, em específico.

A ideia era também investir em atividades que ajudassem a superar a dificuldade de expressão dos alunos, como a observada no primeiro encontro, em que as crianças simplesmente não sabiam o que sentiam a respeito do livro. No encontro em questão, o objetivo foi saber o tamanho da dificuldade que os alunos tinham em entender seus próprios sentimentos e, para isso, foram solicitados a listar todos os sentimentos, sensações e emoções que conheciam, separadamente, ou seja, que fizessem uma contabilidade da repetição das palavras, e notamos que sentimentos como alegria e paixão se misturavam com sentimentos como alegria e amor, da mesma forma que sensações como calor eram misturadas com sentimento de agonia. O que se pode notar foi que o vocabulário acerca da temática era bem limitado, apresentando nenhuma ou poucas vezes palavras como angústia, alívio, agonia, conforto, raiva, paz, dor, prazer, irritação, ansiedade, satisfação etc.

A hipótese foi de que esse desconhecimento dos aspectos do sentir humano não era apenas um fator ligado à idade, pois, afinal, todos ali já haviam entrado ou estavam próximos da adolescência, mas um reflexo das formas de relação que estes alunos vivenciavam, tanto na escola como na sociedade de forma geral, onde o aspecto subjetivo não parece ser valorizado e/ou visado.

A atividade seguinte só ajudou a confirmar essa dificuldade. Ali, cada um deveria pegar algum dos livros da biblioteca, sem antes ter lido seu conteúdo, e descrever o que a capa lhe causava e o porquê. Em sua maioria, os alunos não sabiam como começar, e só conseguiam falar sobre o que a capa causava a eles com muita interferência dos bolsistas. Ainda assim, alguns resultados eram simples descrições literais dessas capas. Aparentemente, sentiam dificuldade em se expressarem por conta principalmente de um desconhecimento do vocabulário e/ou até mesmo do próprio sentimento. E, para verificar o fato, levamos os alunos para um espaço aberto, arborizado e essencialmente diferente das salas de aula convencionais; afinal, talvez uma 
ambiente mais amplo e distante da ideia de exatidão, rigidez e convencionalmente racional pudesse ser positivo para essa atividade, que buscava explorar o subjetivo e o sensorial.

Antes de que todos pudessem chegar ao local da atividade, foi proposta uma atividade que tinha como foco observar se eles confiavam uns nos outros e se eram capazes de combinar suas subjetividades e complexidades individuais (no caso os sentidos, a capacidade de orientar e confiar). A questão era: como reagiriam quando fossem conduzidos por um dos colegas enquanto estivessem vendados?

Logo nos primeiros passos, a euforia tinha se instaurado novamente, quase todos chegaram até o local selecionado sem nenhum problema e, ainda que fizessem alarde, todos pareciam alegres e de acordo com o que acontecia. Contudo, pelo menos uma das garotas, entre doze e treze anos de idade, que no quarto encontro havia feito parte de um grupo de quatro amigas, entrou em pânico e não conseguiu continuar, segundo ela mesma, por desconfiança nos outros. Pode-se notar que os integrantes deste grupo de alunas passaram por problemas consecutivos com as atividades, deixando perceber comportamentos "antissistêmicos", cuja explicação neste artigo será dada posteriormente.

Para seguir com a atividade, todos se sentaram com vendas nos olhos e foram estimulados a identificar sons, cheiros, sabores e características dos vários objetos entregues, para que tentassem descrever o que sentiam sem serem literais. (Fig.3)

Fig.3 - Sensação cheiro (arquivo do pesquisador)

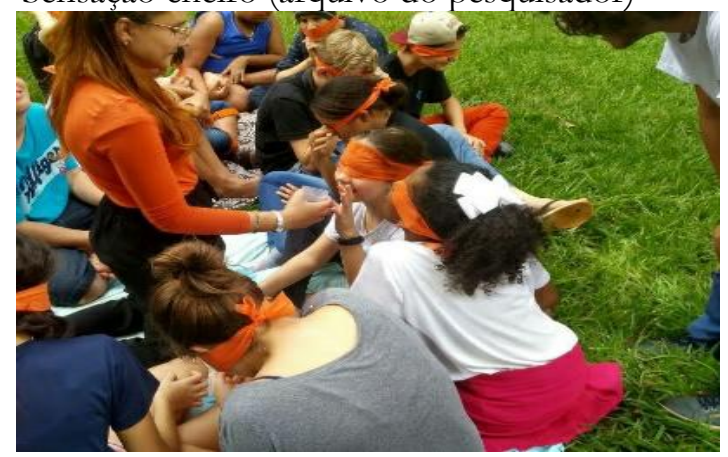

O objetivo foi estimular o lado subjetivo, emocional e sensorial dos alunos, para aumentar o conhecimento e seus repertórios quanto às sensações, como uma alternativa para ajuda-los a desenvolver a empatia e a comunicação, que até então era feita, a maioria das vezes, com gritos e interrupções.

Paralelamente, pode-se notar que dois alunos entre quatorze e quinze anos não queriam participar da atividade e ficaram inquietos sem nenhum interesse pelo que era proposto, enquanto os mais novos, de onze e treze 
anos, que eram maioria, estavam com dificuldade, mas tinham curiosidade e comprometimento com a proposta. Ao contrário, um dos alunos com deficiência presente à atividade tinha muito mais facilidade do que os outros para descrever o que ele sentia, sem inclusive a necessidade de uma palavra específica para isso.

Fig. 4 - Sensação tato (arquivo do pesquisador)

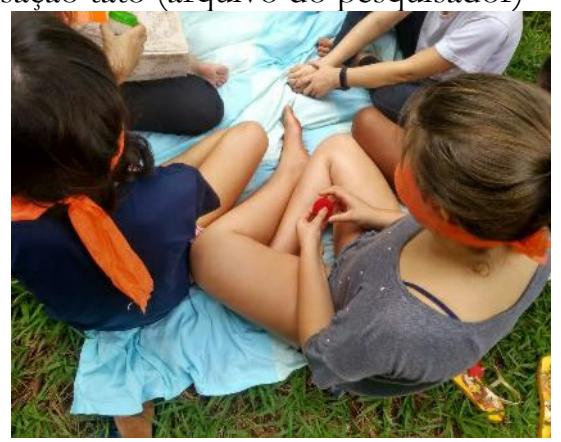

Naquele mesmo dia, este aluno havia trazido umas cartas para um outro trabalho do período regular de aulas, um grande cartaz sobre a diversidade, feito todo com colagens, que já tinham chamado a atenção no começo do encontro; e quando um grande chocalho cilíndrico passou por suas mãos e ele escutou o longo som dos grãos em seu interior, disse: "É um foguete no céu!". Por mais que aquela definição fosse "inobjetiva", com certeza era subjetiva e lógica, pois é fácil imaginar um grande cilindro que produz um alto chiado como um foguete e, uma vez que seus olhos estavam vendados, o garoto recorrer ao seu repertório de sensações para definir o que não podia identificar objetivamente com os olhos.

Essa atividade demonstrou, novamente, que os alunos ditos "normais" têm enorme dificuldade para se expressar, sobretudo em idade superior, tanto pelo fato de não terem palavras ou conceitos para a maioria das sensações oferecidas, quanto pela dificuldade de associar estas sensações a um campo subjetivo, as suas próprias emoções. Ainda, a atividade mostrou que os alunos considerados "deficientes" eram muito capazes de participar ativamente da mesma atividade, na mesma sala de aula, sem a necessidade de um ambiente que diferenciasse o ensino, onde fossem ou se sentissem segregados.

Nos sétimo e oitavo encontros, foi colocado em um trabalho coletivo tudo que conseguimos provocar nas crianças sobre o sentir. Esse trabalho foi denominado "Dicionário das Sensações AEE" (Fig.5).

Fig.5 - Dicionário das sensações (arquivo do pesquisador) 


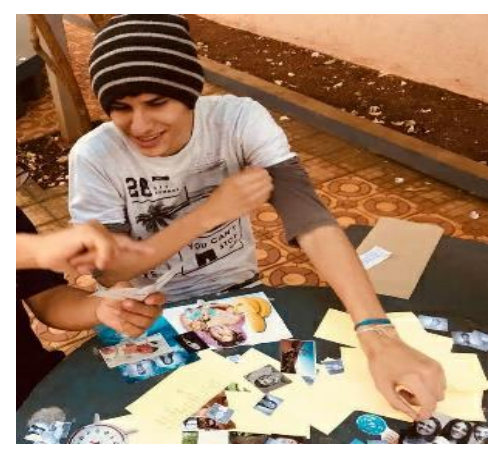

Nesse trabalho, os alunos deveriam tentar definir as sensações que haviam explorado depois da última atividade. Para isso, utilizaram recortes de revistas e desenhos associados a definições escritas breves, sobre as imagens que eles deveriam selecionar. Exercitando a criação de uma rede intersubjetiva de relações, apropriando-se da complexidade de suas potencialidades e individualidades, e apoiando-se na instabilidade dos conceitos emocionais aos quais se focavam, talvez pudessem, enfim, expandir seu conhecimento sobre as sensações, construindo um dicionário conjunto reunido sob uma perspectiva inclusiva e sistêmica de educação.

Todos pareciam bem animados com a atividade e os próprios alunos se dividiram em duas equipes (Fig.6). Uma equipe "das definições" cuidaria de selecionar as imagens para cada sensação, sentimento e emoção que eles conheciam, enquanto a outra ficaria responsável por criar uma capa, seguindo a ideia de um dos garotos, usando seus conhecimentos em edição de imagem no computador da escola. 
Fig.6 - Definições (arquivo do pesquisador)

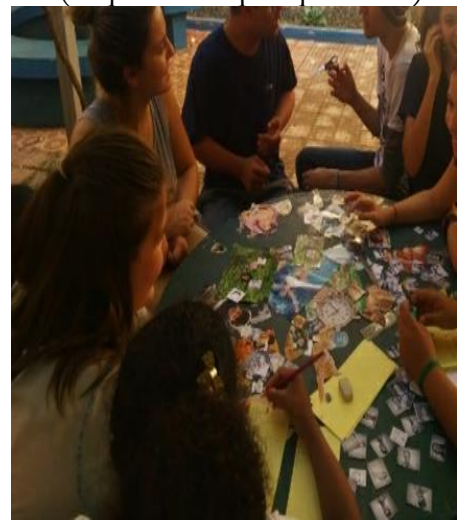

O projeto ocorreu relativamente bem no primeiro dia, mas no oitavo encontro o ritmo da atividade ficou muito lento. Possivelmente, o problema estava na divisão do trabalho entre os membros, pois novamente as mesmas meninas que formaram um único grupo no quarto encontro tinham muita dificuldade de trabalhar em conjunto com outras pessoas, e muitas vezes até entre elas. Segundo a observação dos bolsistas, essas meninas tinham uma tendência a serem autoritárias, fazendo o que queriam quando queriam e sem questionar a opinião de nenhum outro membro do grupo, o que resultava em muitas brigas, desacordos e dificuldades na execução do trabalho coletivo.

É em relação a isso que o termo "antissistêmico" foi cunhado: um comportamento diretamente contrário ao exercício do pensamento sistêmico aplicado a uma ótica inclusiva, pois impede que os três pilares desta teoria se sustentem. $\mathrm{Na}$ situação em questão, quando presente em algum dos componentes do sistema, o autoritarismo impossibilita a intersubjetividade, uma vez que impede a ponderação de questões e a existência de outras percepções diferentes do sujeito autoritário.

Enquanto isso, na segunda equipe, um dos garotos desistiu da ideia sem avisar e migrou-se para um outro grupo. Posteriormente, em conversa com ele, ficou evidenciado que tinha um histórico de exclusões e bullying, e mesmo o projeto sendo fundamentado na inclusão, ele não se sentia parte do grupo, alegando ter-se afastado para a outra equipe justamente porque seus colegas não o queriam por perto. Para tentar solucionar a questão, todos foram chamados para uma conversa franca, e os bolsistas reiteraram o objetivo do projeto e das últimas atividades, sobre a construção de um grupo inclusivo cujo foco é aprender. Nos últimos encontros, por conta de situações de exclusão e violência como as que esse garoto vinha passando, o tema ficou centrado no conceito de empatia. Não obstante, ainda fruto dessa situação, um segundo comportamento antissistêmico foi identificado: a segregação. Quando ocorre a segregação, a ampliação do conhecimento relacionado a um 
objeto fica comprometido, justamente porque é excluída do sistema uma das possíveis perspectivas, a do observador segregado.

Todos os presentes ouviram o desabafo de indignação dos bolsistas, dois relataram não saber o que estava ocorrendo e as mesmas garotas de antes disseram que sempre discutiam com o garoto porque ele era muito inconveniente e invasivo, sempre buscando atenção. De fato, em alguns momentos este menino costumava se colocar acima dos outros, falando alto e interrompendo seus colegas, sempre querendo ser o primeiro em tudo; na verdade, tal como agia uma das meninas. Finalmente, o encontro foi encerrado com pedidos de desculpas pelos participantes.

O décimo encontro objetivou a finalização do projeto do dicionário e ocorreu em uma sala de aula. Entretanto, diferentemente de todas as outras reuniões, uma tensão foi se instalando no ambiente por conta da dificuldade que eles ainda tinham de trabalhar em grupo. Apesar de todas as reclamações sobre o prolongamento da atividade, os bolsistas tentaram manter os grupos ligados ao trabalho até que terminassem e apresentaram formas de organização possíveis, uma vez que ao invés de ser colaborativa, coletiva, a atividade havia se tornado uma competição, desviando completamente do propósito original de se constituir um trabalho comum. As discussões sem fim, por conta da postura autoritária de uma das garotas, tornaram-se motivo para uma disputa entre qual modelo das páginas do dicionário era o melhor.

Nesse momento, estava evidenciado o último pilar "antissistêmico". A competição dentro de um sistema que se propõe ou depende de uma coletividade para existir é a sua própria ruína, visto que impede que as relações convirjam para um mesmo foco, um objetivo em comum atrapalhando o equilíbrio já fragilizado do sistema, assim a competição atinge diretamente a complexidade pela perda de componentes.

$\mathrm{Na}$ tentativa de promover mais descontração, foi sugerida música ambiente, mas quando mais uma vez a questão da coletividade, ao invés do autoritarismo, foi apontada a mesma garota teve uma crise de ansiedade. A imagem foi aterradora: uma criança de doze anos chorando e tentando falar sobre pressões psicológicas, com muito desespero. De fato, situações de instabilidade emocional como essa parecem ser comuns entre adolescentes e jovens adultos, em boa parte por conta do grande volume de responsabilidades, expectativas e pressões sociais impostas nesta faixa etária, mas ali ficava evidente que estas pressões têm aumentado em todos os níveis, inclusive entre crianças e pré-adolescentes. Como mostram estudos da Organização Mundial da Saúde (OMS), o Brasil tem o maior número de pessoas ansiosas do mundo, com cerca de 18,6 milhões de brasileiros vítimas de ansiedades diversas. E boa parte do que a garota dizia demonstrava uma incompreensão do que ela sentia, e do que era necessário mudar na forma de tratamento e organização que ela e todo grupo precisavam fazer. Dificilmente renunciavam a algum posicionamento, ideia ou vontade para chegarem a um consenso, tão pouco confiavam um no outro para fazer o seu melhor. 
No encontro seguinte, fizemos uma atividade para descontrair e estimular o trabalho em equipe mostrando de maneira prática o poder da interdependência e o quanto eles poderiam realizar quando trabalhassem juntos colocando suas particularidades. A atividade consistia em um jogo cujo objetivo era transportar de um lado a outro de uma quadra alguns objetos, sem usar as mãos, bocas ou pés. Com uma ou duas dicas, eles acabaram carregando todos os itens, uma folha de papel, uma caneta, um sapato, dentre outros. Depois disso, voltaram à sala, terminaram e concluíram, um pouco menos tensos, a última parte do trabalho, a capa coletiva do projeto do dicionário. Depois disso, o projeto ainda teve alguns encontros não documentados, porém com pouca relevância e material de análise.

Fig.7 - Capa coletiva (arquivo do pesquisador)

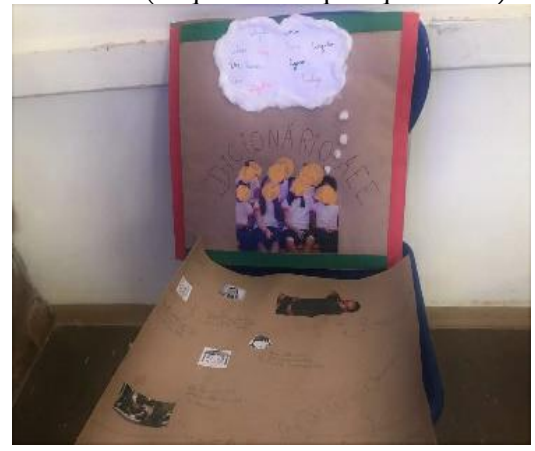

\section{Considerações finais}

Do início do projeto até aqui, foram pontuadas algumas questões: em primeiro lugar que, desde o primeiro dia, a maioria dos alunos entre onze e treze anos estavam extremamente empolgados e curiosos com o que seria desenvolvido, embora não seja possível quantificar o que eles assimilaram e desenvolveram a partir da proposta; no geral, o que se notou é que uma boa parcela dos alunos se manteve extremamente engajado, do começo ao fim, pelas respostas ao final de algumas reuniões e por pedidos de continuação das atividades mesmo alguns meses seguintes ao término do AEE. Além disso, durante o período do projeto eles sempre se preocupavam em justificar com antecedência quando tinham que faltar.

Por outro lado, a grande maioria dos alunos de quatorze anos ou mais se afastou do projeto. Alguns justificaram que não tinham mais tanto tempo, por conta do ensino médio ou de provas finais, embora tivessem participado ativamente desta e de outra experiência de AEE realizada seis meses antes. Houve também aqueles que, apenas para atender ao convite da professora 
coordenadora, visitaram o projeto e abandonaram a atividade logo no princípio ou após um dia de participação.

Em resposta à questão "Se e como uma escola que valoriza as diferenças e reconhece as individualidades pode potencializar o desenvolvimento de todos os envolvidos?", a princípio a hipótese era de que bastavam mais investimentos em políticas públicas e novas metodologias; o que, ao final, demonstrou ser muito mais complexo. A mudança necessária para transformar a escola em um espaço inclusivo depende também da "curiosidade natural da juventude", que se perde em ambientes educacionais que segregam e estabelecem distâncias entre os alunos. A reunião de alunos mais novos, com uma natureza curiosa mais preservada, que não foram silenciados ou segregados de si mesmos, pode ser uma alternativa para burlar este estado de coisas. Mas há ainda o fato de a escola não ser a única responsável por impedir a segregação, pois outros ambientes formadores, como a família, o trabalho, as relações sociais de outra natureza também têm se sustentado em alguma fonte de autoridade e violência.

A inclusão é, sim, importante; é, sim, uma alternativa para diminuir a segregação e a violência. Mas, acima de tudo, é preciso uma mudança multilateral nas estruturas sociais e, sobretudo, em suas raízes. Afinal, temos crianças cometendo atrocidades inaceitáveis (talvez advindas das atitudes de adultos), como o assédio, a misoginia e bullying, que são apenas uma fração das violências observadas em seres humanos, e que refletem contra nós mesmos traduzidas em ansiedade, incapacidade de compreensão emocional, dificuldade de expressão, de socialização, de cooperação, dentre muitos outros problemas que podem ter passado desapercebidos durante o projeto.

O que a tendência educacional positivista parece cristalizar são as ideias científicas que se comprometem a seguir um caminho "positivo", do avanço e da "ordem e progresso", mas que, no fim, nos levam à guerra, em nome de um desenvolvimento que tem o sentido de desfazer, ou de retirar o envolvimento. Trata-se, pois, de um "antissistema”, que é, por si só, a ruína de tudo que vivemos, traduzido em distância, desconexão, incompreensão, angústia, violência, dor e morte.

É fato que o sistema educacional brasileiro está, há muitos anos, em crise; também é fato que a questão da inclusão está sendo colocada em discussão há décadas, já que pesquisas, trabalhos, propostas e experimentos vêm sendo feitos para tentar transformar esta triste realidade. Porém, aparentemente, muito pouco tem realmente se concretizado para que uma reforma ou um plano educacional seja colocado em prática, como um todo, pela nação. Assim, este trabalho soma-se a outros que buscam a mudança lançando ao ar fagulhas sobre alguns dos reflexos da exclusão e dos princípios "antissistêmicos" no atual "sistema" social e educacional. 


\section{Referências}

BRASIL, Constituição Federal. Congresso Nacional: Brasília. 1988.

MANTOAN, Maria Teresa Eglér. Inclusão escolar: o quê? por quê? Como fazer? 1.Ed. São Paulo:Moderna, 2002.

ORTHOF, Sylvia. Quem roubou o meu futuro? 7. ed. São Paulo: Atual, 1989. Ilustrações: Júlio Fischer.

VASCONCELlOS, Maria José Esteves de. Pensamento Sistêmico: o novo paradigma da ciência. 10 ed. São Paulo: Papirus, 2002.

Recebido em: 19 nov. 2020

Aceito em: 17 dez. 2020 